\author{
Marquette University \\ e-Publications@Marquette
}

2002

\title{
An XPS Investigation of Thermal Degradation and Charring of PMMA Clay Nanocomposites
}

Jianxin Du

Beijing Institute of Technology

Jin Zhu

Marquette University

Charles A. Wilkie

Marquette University, charles.wilkie@marquette.edu

Jiangqi Wang

Beijing Institute of Technology

Follow this and additional works at: https://epublications.marquette.edu/chem_fac

Part of the Chemistry Commons

\section{Recommended Citation}

Du, Jianxin; Zhu, Jin; Wilkie, Charles A.; and Wang, Jiangqi, "An XPS Investigation of Thermal Degradation and Charring of PMMA Clay Nanocomposites" (2002). Chemistry Faculty Research and Publications. 154. https://epublications.marquette.edu/chem_fac/154 


\title{
Marquette University
}

\section{e-Publications@Marquette}

\section{Chemistry Faculty Research and Publications/College of Arts and Sciences}

This paper is NOT THE PUBLISHED VERSION; but the author's final, peer-reviewed manuscript. The

published version may be accessed by following the link in th citation below.

Polymer Degradation and Stability, Vol. 77, No. 3 (2002): 377-381. DOI. This article is (C) Elsevier and permission has been granted for this version to appear in e-Publications@Marquette. Elsevier does not grant permission for this article to be further copied/distributed or hosted elsewhere without the express permission from Elsevier.

\section{An XPS investigation of thermal degradation and charring on PMMA clay nanocomposites}

\author{
Jianxin Du \\ School of Chemical Engineering and Materials Science, Beijing Institute of Technology, 100081 Beijing, \\ China \\ Jin Zhu \\ Department of Chemistry, Marquette University, Milwaukee, WI \\ Charles A. Wilkie \\ Department of Chemistry, Marquette University, Milwaukee, WI \\ Jianqi Wang \\ School of Chemical Engineering and Materials Science, Beijing Institute of Technology, 100081 Beijing, \\ China
}

\footnotetext{
Abstract

Poly(methyl methacrylate)-clay nanocomposites have been studied using X-ray photoelectron spectroscopy. It is clear that as the polymer undergoes thermal degradation, the clay accumulates at the surface and the barrier properties which result from this clay accumulation have been described as the reason for the decreased heat release rate for nanocomposites. The surface composition of the clay changes as the nanocomposite is heated and the changes are affected by the organic-modification that were applied to the clay in order to prepare the nanocomposite.
} 


\section{Keywords}

XPS, PMMA-clay nanocomposites, Thermal degradation, Charring

\section{Introduction}

There has been a great deal of interest in nanocomposites recently, because the combination of a polymer with $3-5 \%$ of an organically modified clay shows enhanced mechanical properties. For instance, a nylon-clay nanocomposite, containing $5 \%$ clay, shows a $40 \%$ increase in tensile strength, $68 \%$ in tensile modulus, $60 \%$ in flexural strength and $126 \%$ in flexural modulus, while the heat distortion temperature increases from 65 to $152{ }^{\circ} \mathrm{C}$ and the impact strength is lowered by only $10 \%{ }^{[1]}$. It also exhibited lower water sensitivity and permeability to gases, along with no loss of clarity in the polymer.

Polymer-clay nanocomposites have been prepared by polymerization techniques, including bulk, suspension, emulsion and solution polymerization, and by melt blending and solution blending [2], [3] . Since the polymer must insert into the clay, it is essential that the sodium cation, which is normally the counter-ion in the clay, be replaced by a more organophilic cation so that a polymer is able to penetrate between the clay layers. The combination of a clay with a polymer may give either a microcomposite, also known as an immiscible nanocomposite, in which the clay is present mostly as a filler, or a nanocomposite. If the registry between the clay layers is maintained, the material is referred to as an intercalated nanocomposite. If this registry is lost, it is described as an exfoliated, also known as delaminated, nanocomposite.

In addition to mechanical properties, fire properties, notably heat release rates from cone calorimetric experiments, are also reduced, typically by $50 \%$ or more for both intercalated and exfoliated materials $[4],[5],[6],[7],[8],[9],[10]$. Among the many polymers that have been examined are polyamide 6 , polyamide 12 , polystyrene, poly(methyl methacrylate) and polypropylene-graft-maleic anhydride. Two mechanisms have been suggested to account for the reduction in heat release rate, a barrier mechanism, in which the clay functions as a barrier to insulate the polymer from the fire and a barrier to mass transfer of the polymer $\stackrel{[11]}{\text {, and }}$ a radical trapping mechanism, which occurs due to the presence of iron, or other paramagnetic impurities, as a structural component in the clay $\stackrel{[12]}{ }$.

In studies from these laboratories, we have examined the X-ray photoelectron spectra, XPS, of polystyrene-clay nanocomposites ${ }^{[13]}$. This work shows that carbon is lost and oxygen accumulates at the surface of the degrading polymer, thereby confirming the barrier properties as a mechanism by which these materials function. Current thinking is that the radical trapping mechanism is most important at lower amounts of clay while the barrier mechanism becomes more important as the fraction of clay increases.

In this work, we extend the XPS studies to include work on poly(methyl methacrylate) (PMMA)-clay

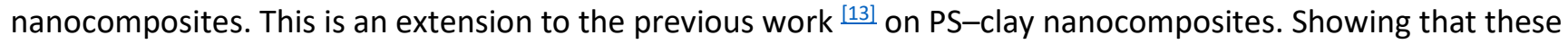
observations are applicable to more than one polymer increases the generality of the observations.

\section{Experimental}

The preparation and characterization of the PMMA nanocomposites has been previously described ${ }^{[14]}$. Three organo-clays were prepared by ion exchange between a sodium clay (generously supplied by Southern Clay Products) and an ammonium salt on which the substituents are a benzyl, two methyls and a long $\left(\mathrm{C}_{16}\right)$ hydrocarbon chain (benzylhexadecyldimethylammonium, known herein as Bz16), an allyl, two methyls and the same long chain (allylhexadecyldiemthylammonium, allyl16) or a styryl, two methyl and the same long chain (styrylhexadecyldiemthylammonium, VB16). These ammonium salts were prepared in these laboratories, as previously described ${ }^{[14]}$. The nanocomposites were prepared by bulk polymerization, using azobisisobutyronitrile (AIBN) as the initiator. The XPS experiments were carried out as previously 
described [15], [16]. The spectra were obtained using a Perkin-Elmer PHI 5300 ESCA system at $250 \mathrm{~W}$ (12.5 kV at 20 $\mathrm{mA}$ ) under a vacuum better than $10^{-6} \mathrm{Pascal}\left(10^{-8} \mathrm{Torr}\right)$. The spectrometer was calibrated using the binding energy of adventitious carbon as $284.6 \mathrm{eV}$. The samples were prepared by solvent casting a thin film from a dichloromethane solution onto aluminum foil. The $d$-spacing of the nanocomposite before and after dissolution was determined and no change was found. The pseudo-in situ technique was utilized. In this technique the sample is heated outside of the XPS chamber under an argon atmosphere and then the sample is placed in the XPS chamber for analysis $[15$, , 16$]$.

\section{Results and discussion}

The PMMA nanocomposites that have been examined include one which is largely intercalated, the ammonium cation is benzylhexadecyldimethylammonium ion (Bz16), and two materials which are a mixture of intercalated/exfoliated, allylhexadecyldimethyl ammonium ion, (allyl16); and styrylhexadecyldimethyl ammonium ion (VB16). The thermogravimetric analysis of these nanocomposites shows three distinct regions of degradation. Kashiwagi $\stackrel{[17]}{ }$ has studied the thermal degradation of virgin PMMA and has identified these three steps as due to the degradation of weak links in the polymer chain, degradation arising from end-chain unsaturation, and, the third and largest step, is ascribed to random scission. The initial step is absent in VB16 and is greatly diminished in the other two materials. The change has been attributed to a templating effect from the clay directing the formation of the PMMA; this idea originated with some of the pioneering work of Blumstein on the synthesis of methacrylate polymers in the presence of clays $\frac{[18]}{\text {. }}$

The carbon 1s and oxygen 1s spectra, along with data for silicon and aluminum, have been obtained for virgin PMMA and its nanocomposites. Fig. 1 shows the relative intensity in the C1s spectra of virgin PMMA as a function of temperature.

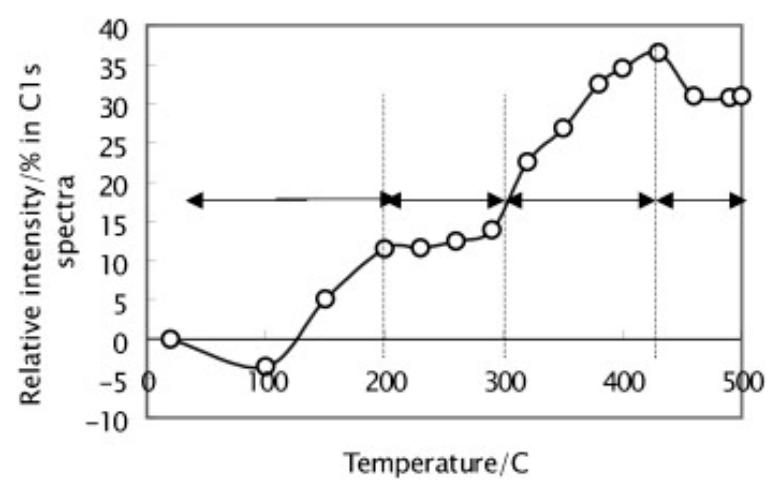

Fig. 1. Relative intensity in C1s spectra as a function of temperature for poly(methylmethacrylate) (PMMA).

It must be noted that a negative peak is a common feature in XPS and is attributed to the loss of surface contamination. An increase in the intensity due to $\mathrm{C} 1 \mathrm{~s}$ implies that other elements, probably hydrogen-rich fragments, are lost from the surface. This probably leads to the formation of radicals or double bonds, which can lead to a loose cross-linking of the polymer chains. Thus, accumulation of carbon is frequently ascribed to crosslinking processes; nevertheless, this may not correspond to cross-linking as usually measured by gel content method, rather here the process probably describes some loose interaction between radical fragments at the surface. The data are shown in Fig. 1 and has been divided into four regions, which roughly correspond to the three steps of PMMA degradation noted earlier [17]. The accumulation of carbon that begins a little above $100{ }^{\circ} \mathrm{C}$ in the first region probably occurs because cleavage of the weak links (the cleavage of head-to-head links is reported to occur in this region) will form radicals which may hydrogen abstract from other polymer chains and ultimately lead to cross-linking. The intensity in the $\mathrm{C} 1$ s spectrum is somewhat constant over region 2, which probably means that little change in the polymer occurs in this region. This is the region in which the degradation of polymer chains that are terminated with unsaturated groups occurs. This degradation produces 
monomer and a new unsaturated group which can degrade and thus would not be expected to lead to crosslinking and accumulation of carbon. When the temperature exceeds $300^{\circ} \mathrm{C}$, a rapid increase in intensity is seen; this is the region in which random scission begins. Random scission may lead to either the accumulation of carbon, if the radicals recombine, or to the loss of carbon as small fragments are produced. It is apparent that between 300 and $400{ }^{\circ} \mathrm{C}$ the dominant reaction is accumulation from radical combinations. Above $400{ }^{\circ} \mathrm{C}$ the intensity decreases and the dominant reaction is the formation of small, volatile fragments.

The process of degradation and charring can also be examined by exploring the formation of organized carbon, as measured by the plasmon loss curves as a function of temperature, shown in Fig. 2. An increase in the plasmon loss value is correlated with the extent of organization of carbon, and hence to cross-linking. One can clearly see that this parameter increases up to $400{ }^{\circ} \mathrm{C}$ and then remains at a constant value. The interpretation is that cross-linking occurs up to $400{ }^{\circ} \mathrm{C}$ and that degradation of this cross-linked material occurs above this point.

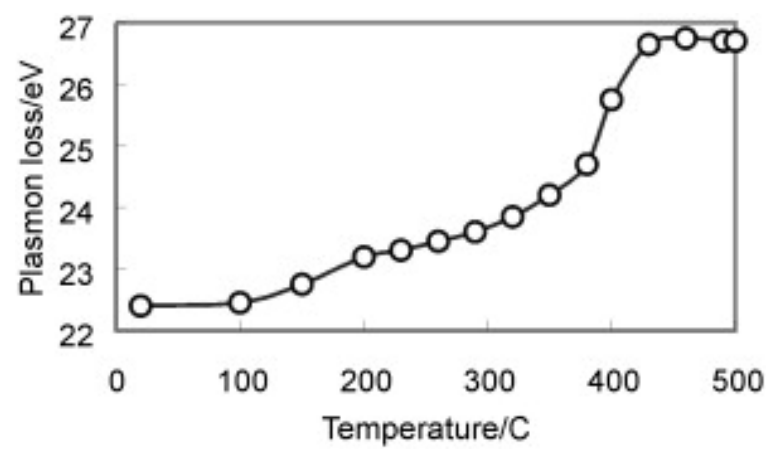

Fig. 2. Plasmon loss in the C1s spectra as a function of temperature for poly(methylmethacrylate) (PMMA).

The O1s spectra, shown in Fig. 3, agree with the observations from C1s. The accumulation of oxygen is seen to increase up to $380^{\circ} \mathrm{C}$ and then show a rapid decrease above this temperature. The accumulation of oxygen indicates that even though these experiments are conducted in an inert atmosphere, oxygen is still present and in sufficient quantities to react with the radicals produced during the degradation. Above $380^{\circ} \mathrm{C}$, the rapid loss of oxygen corresponds to pyrolysis reactions leading to the formation of small volatile fragments.

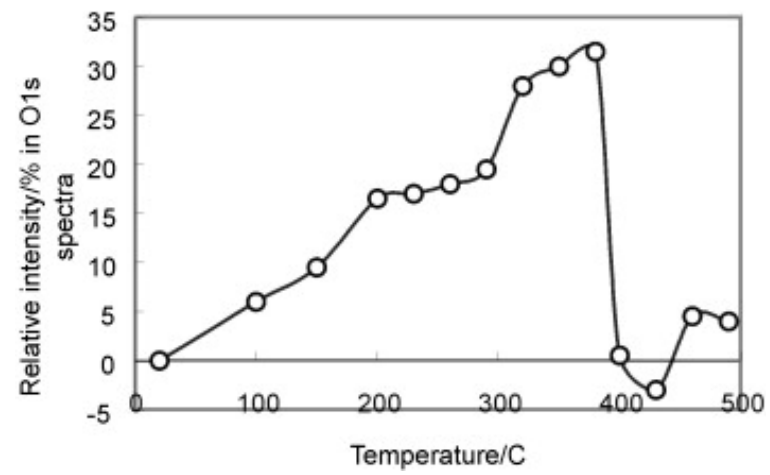

Fig. 3. Relative intensity in 01s spectra as a function of temperature for poly(methylmethacrylate) (PMMA).

It is of interest to compare the C1s spectra of PMMA with that of PS (polystyrene) and this comparison is shown in Fig. 4. It is obvious that carbon accumulates more easily in PMMA than in PS and the usual interpretation of this is that PMMA undergoes a more facile cross-linking than does PS. Similar information is shown in Fig. 5 in which the plasmon loss data for both PMMA and PS are shown. This data suggests that more organization of carbon occurs for PMMA than for PS. 


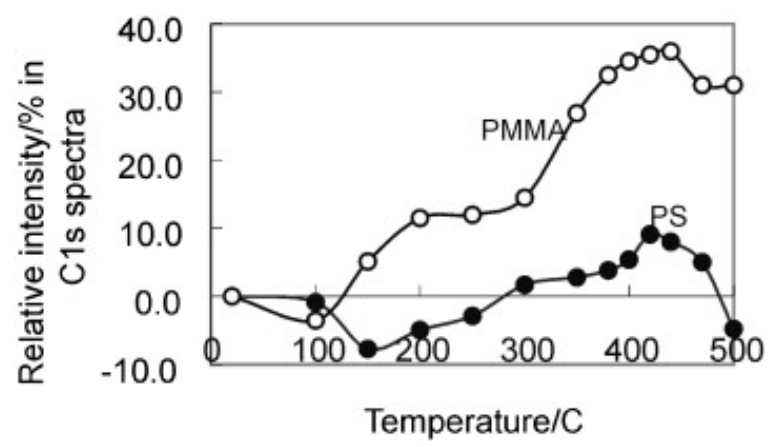

Fig. 4. Relative intensity in the C1s spectra as a function of temperature for both poly(methylmethacrylate) (PMMA) and polystyrene (PS).

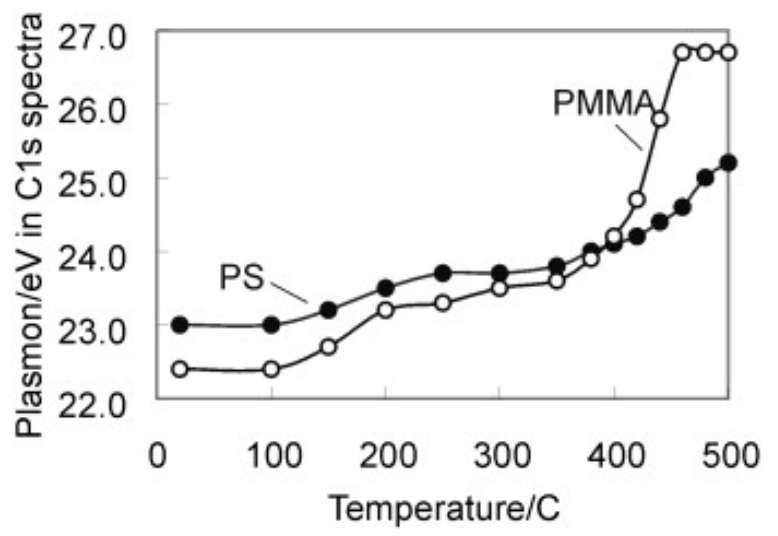

Fig. 5. Plasmon loss as a function of temperature for both poly(methylmethacrylate) (PMMA) and polystyrene (PS).

The formation of a nanocomposite causes a remarkable difference in the $\mathrm{C} 1 \mathrm{~s}$ spectra, as shown in Fig. 6 . Above $300{ }^{\circ} \mathrm{C}$, the relative intensity of carbon in the nanocomposites decreases while it continues to rise for virgin PMMA. The behaviour of the nanocomposites is about the same as the virgin polymer below $300^{\circ} \mathrm{C}$, but the intensity is a bit lower, except for the VB16 material. The significantly reduced accumulation of carbon at the surface above $300^{\circ} \mathrm{C}$ needs further explanation (see later). From Fig. 7 one can see that the extent of organization is lower for the nanocomposites than for the virgin polymer. This may imply a somewhat higher thermal stability for the polymer, which leads to decreased formation of radicals and thus a decrease in crosslinking.

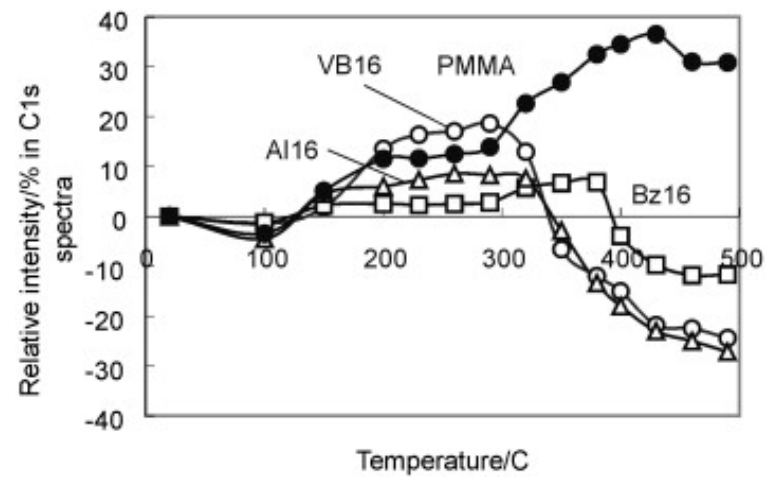

Fig. 6. Relative intensity in the C1s spectra for poly (methylmethacrylate) (PMMA) and its nanocomposites. 


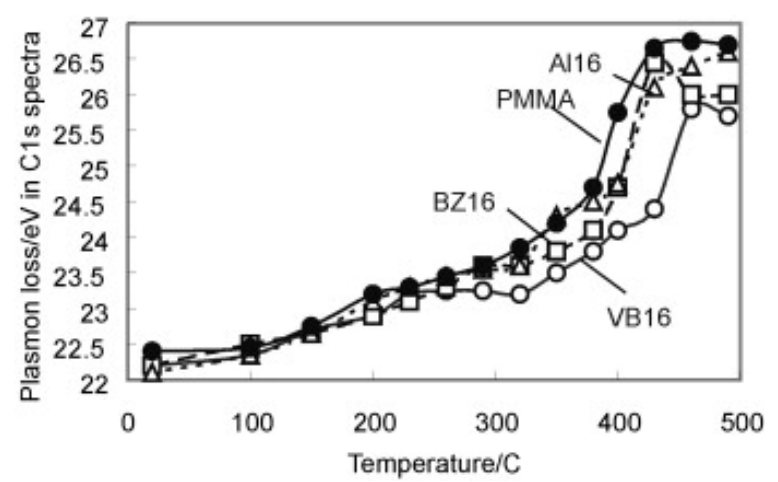

Fig. 7. Plasmon loss for poly(methylmethacrylate) (PMMA) and its nanocomposites.

The 01s spectra, shown in Fig. 8, for PMMA-clay nanocomposites are quite similar to those of the virgin polymer below $380^{\circ} \mathrm{C}$, but there is a dramatic change above this temperature. In the virgin polymer, the oxygen intensity decreases while for the nanocomposites an increase is observed. For the virgin polymer the decrease was attributed to the commencement of pyrolysis and the loss of the polymer. The same explanation holds for the nanocomposites, as the polymer is lost the aluminum silicates accumulate at the surface and the accumulation of oxygen increases. This is in agreement with our previous work on PS-clay nanocomposites $\frac{[13]}{\text {, }}$

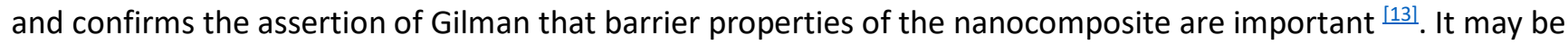
significant to note that the smallest accumulation of oxygen occurs for the completely intercalated Bz16. The random distribution of clay layers found in an exfoliated material may cause a more effective accumulation of clay at the surface.

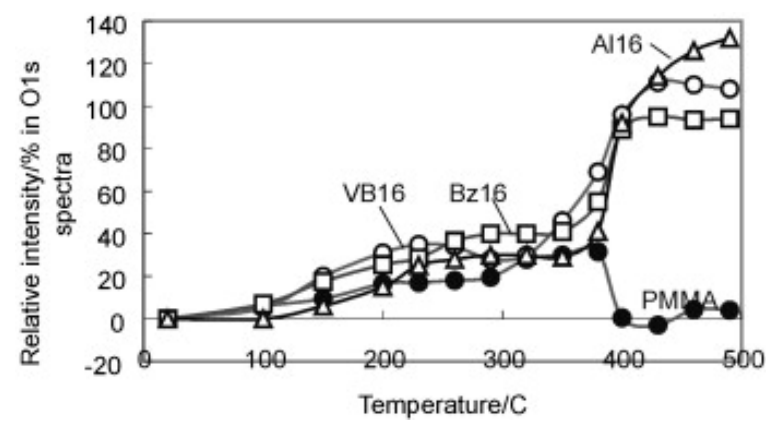

Fig. 8. Relative intensity in the O1s spectra for poly (methylmethacrylate) (PMMA) and its nanocomposites.

These results cannot evaluate the relative effectiveness of the barrier mechanism versus the radical trapping process. Based upon previous work, it has been suggested that radical trapping is only effective at low clay concentrations, where one cannot build up a sufficient quantity of clay to act as the barrier. These results do confirm that as the polymer is lost from the surface, the clay accumulates at the surface and could function as a barrier. There is no clear indication that this barrier is effective, only that it is formed.

Previous studies using solid state NMR spectroscopy of zeolites $\underline{[19]},[20]$ and XPS measurements on zeolites and on clays $\stackrel{[21]}{~ h a s ~ s h o w n ~ t h a t ~ c h e m i c a l ~ c h a n g e s ~ o c c u r ~ u p o n ~ h e a t i n g . ~ F r o m ~ s o l i d ~ s t a t e ~ N M R, ~ t h e ~ t e t r a h e d r a l ~}$ aluminum-oxygen and silicon-oxygen units are changed into octahedral units. These changes begin at temperatures as low as $280^{\circ} \mathrm{C}$ and lead to the complete destruction of the zeolite.

Fig. 9 shows the silicon:aluminum ratio as a function of temperature. One can clearly see that the ratio falls in the range of $200-300^{\circ} \mathrm{C}$ and that the change in this ratio is dependent upon the particular organic treatment that has been applied to the clay. It is well-known $\underline{[22],[23]}$ that the cations of the clays undergo thermal degradation in this temperature regime; the reaction that occurs is a Hofmann degradation and this leads to the complete loss of the cation and its replacement with a proton as the counter ion of the clay. Since this change in silicon:aluminum ratio occurs in the same temperature region, it is reasonable to suppose that the loss of the 
cation may have some effect on the structure of the clay. Similar changes for the silicon:aluminum ratio in zeolites and in clays have been previously observed by XPS $\underline{[21]}$.

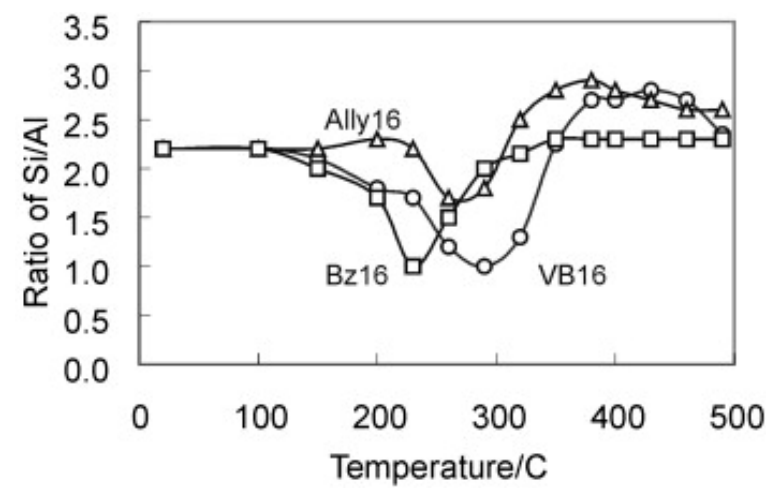

Fig. 9. Ratio of Si:Al for three poly(methylmethacrylate) (PMMA)-clay nanocomposites as a function of temperature.

Information about the changes in chemical composition of clays on heating can be obtained from the changes in binding energies of Si2p spectra as the material is heated, this is shown in Fig. 10. The three nanocomposites show changes in binding energy which are dependent upon the particular organic treatment, exactly as was observed for the changes in the silicon:aluminum ratio. This is another confirmation that the organic treatment has a significant effect on the clay degradation. Binding energies of Al2p gives similar patterns but they are not as sensitive as Si2p spectra. Above $350^{\circ} \mathrm{C}$, the binding energy of $\mathrm{Al} 2 \mathrm{p}$ reaches $75.0 \mathrm{eV}$, indicating the formation of $\mathrm{Al}_{2} \mathrm{O}_{3}$.

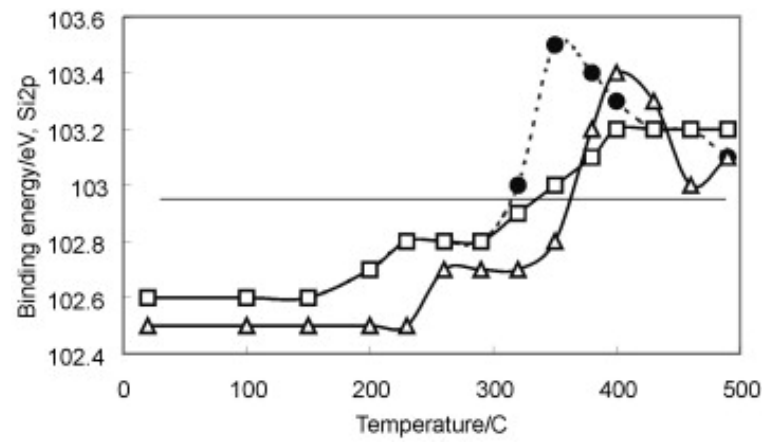

Fig. 10. Binding energy of Si2p for three poly(methylmethacrylate) (PMMA)-clay nanocomposites as a function of temperature.

\section{Conclusions}

XPS measurements on PMMA-clay nanocomposites show that as the polymer undergoes thermal degradation, the clay moves to the surface. At the same time, the clay is chemically changed into some new material and the organic treatment on the clay has an important influence on this chemical change. This work offers support for the notion that the barrier properties of the clay may be important in some circumstances.

\section{Acknowledgments}

The work at Marquette University was performed under the sponsorship of the US Department of Commerce, National Institute of Standards and Technology, Grant No. 70NANBOH0096. 


\section{References}

[1] Y. Kojima, A. Usuki, M. Kawasumi, A. Okada, Y. Fukushima, T. Kurauchi, et al. J. Mater. Res., 8 (1993), pp. $1185-1189$

[2] M. Alexandre, P. Dubois. Mater. Sci., R28 (1) (2000)

[3] Wang D, Zhu J, Wilkie CA. Submitted for publication..

[4] J.W. Gilman, T. Kashiwagi, M. Nyden, J.E.T. Brown, C.L. Jackson, S. Lomakin, et al. S. AlMalaika, A. Golovoy, C.A. Wilkie (Eds.), Polymer additives, I, Blackwell Scientific, London (2000), pp. 249265

[5] J.W. Gilman, T. Kashiwagi, E.P. Giannelis, E. Manias, E. Lomakin, J.D. Lichenhan, et al. M. LeBras, S. Bourbigot, R. Delobel, G. Camino (Eds.), Fire retardancy of polymeric materials, The use of intumescence, Royal Society of Chemistry, Oxford (1998), pp. 203-221

[6] J.W. Gilman. Appl. Clay Science, 15 (1999), pp. 31-49

[7] A.B. Morgan, J.W. Gilman, R.H. Harris Jr., C.L. Jackson. Polym. Mater. Sci. Eng., 83 (2000), pp. 53-54

[8] J.W. Gilman, C.L. Jackson, A.B. Morgan, R.H. Harris Jr., E. Manias, E.P. Giannelis, et al. Chem. Mater., 12 (2000), pp. 1866-1873

[9] J.W. Gilman, A.B. Morgan, R.H. Harris Jr., P.C. Trulove, H.C. DeLong, T.E. Sutto. Polym. Mater. Sci. Eng., 83 (2000), pp. 59-60

[10] A.B. Morgan, J.M. Antonucci, M.R. VanLandingham, R.H. Harris Jr., T. Kashiwagi. Polym. Mater. Sci. Eng., 83 (2000), pp. 57-58

[11] J.W. Gilman, T. Kashiwagi. T.J. Pinnavaia, G.W. Beall (Eds.), Polymer-clay nanocomposites, John Wiley \& Sons, New York (2000), pp. 193-206

[12] Zhu J, Uhl FM, Morgan AB, Wilkie CA. Chem Mater, 2001:12:4649.

[13] Wang J, Du J, Zhu J, Wilkie CA. Polym Degrad Stab [in press].

[14] Zhu J, Start P, Mauritz KA, Wilkie CA. Polym Degrad Stab [in press].

[15] J. Hao, S. Wu, C.A. Wilkie, J. Wang. Polym. Degrad. Stab., 66 (1999), pp. 81-89

[16] J. Hao, C.A. Wilkie, J. Wang. Polym. Degrad. Stab., 71 (2001), pp. 305-315

[17] T. Kashiwagi, A. Inaba, J.E. Brown, K. Hatada, T. Kitayama, E. Masuda. Macromolecules, 19 (1986), pp. 21602168

[18] A. Blumstein, F.W. Billmeyer Jr. J. Polym. Sci., Part A-2 (4) (1966), p. 465

[19] S. Bourbigot, M. Le Bras, R. Delobel, J.-M. Trémillon. J. Chem. Soc., Faraday Trans., 92 (1966), pp. 3435-3444

[20] S. Bourbigot, M. Le Bras, P. Bréant, J.-M. Trémillon, R. Delobel. Fire and Mater., 20 (1996), pp. 145-150

[21] J. Wang, P. Wei, J. Hao. G.L. Nelson, C.A. Wilkie (Eds.), Fire and polymers, materials and solutions for hazard prevention, ACS Symposium Series 797, American Chemical Society, Washington, D.C(2001), pp. 150-160

[22] W. Xie, Z. Gao, W.P. Pan, R. Vaia, D. Hunter, A. Singh. Polym. Mater. Sci. Eng., 83 (2000), p. 284

[23] J. Zhu, A.B. Morgan, F.J. Lamelas, C.A. Wilkie. Chem. Mater., 13 (2001), p. 3774 